8 comunitania)

JULIO / 2014
REVISTA INTERNACIONAL DE TRABAJO SOCIAL Y CIENCIAS SOCIALES INTERNATIONAL JOURNAL OF SOCIAL WORK AND SOCIAL SCIENCES

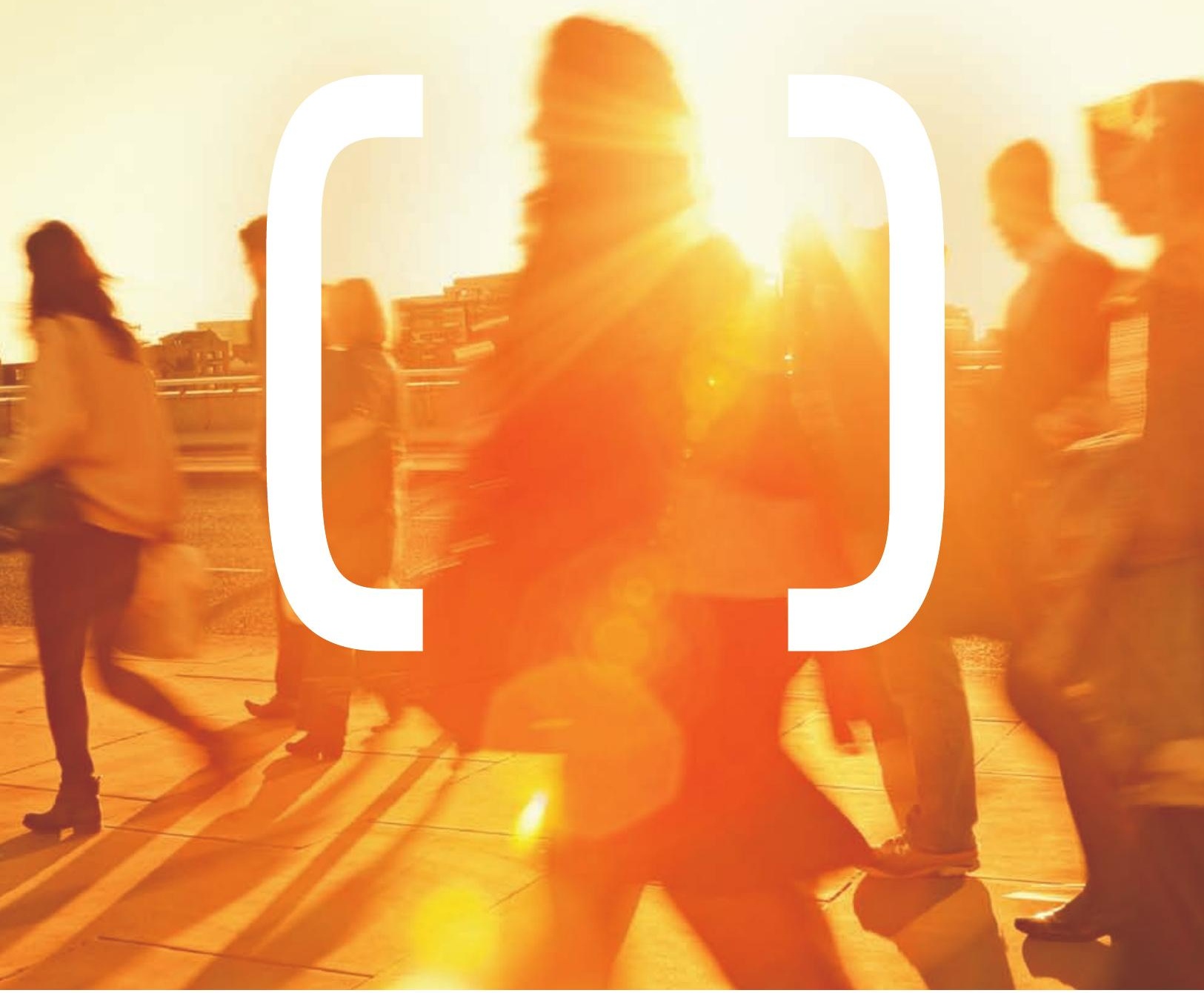

AURELIO TOMMASETTI | ORLANDO TROISI | SILVIA COSIMATO | FRANCESC XAVIER UCEDA I MAZA

MARÍA GARCÍA MUÑOZ | LUCÍA MARTÍNEZ MARTíNEZ | STELLA MARIS SEMINO | RICH FURMAN | MICHELLE D. ENTERLINE GREG LAMPHEAR | ALLISON E. SHUKRAFT | JOSÉ JAVIER NAVARRO PÉREZ | ELISEU V. MARTÍNEZ MUÑOZ | PILAR MONTESÓ-CURTO 


\title{
El territorio y la intervención comunitaria con Adolescentes en Conflicto con la Ley. El Caso del Municipio de Burjassot The territory and the community intervention with teenagers in conflict with law. The case of Burjassot
}

\author{
Francesc Xavier Uceda i Maza", María García Muñoz"“ y Lucía Martínez Martínez"
}

\begin{abstract}
* Trabajador social, sociólogo y Doctor en Desarrollo Local y Territorio. Profesor de Trabajo Social y Servicios Sociales. Instituto Interuniversitario de Desarrollo Local. Universitat de València. Francesc.uceda@uv.es, ${ }^{* *}$ Trabajadora social, socióloga y Máster en Bienestar Social: intervención individual, familiar y comunitaria. Responsable del programa de medidas judiciales del Ayuntamiento de Burjassot. maria.mmjj@gmail.com, ${ }^{* * *}$ Trabajadora social, socióloga y Máster en Gestión y Promoción del Desarrollo Local. Profesora de Trabajo Social y Servicios Sociales. Instituto Interuniversitario de Desarrollo Local. Universitat de València. Lucia.martinez-martinez@uv.es
\end{abstract}

\begin{abstract}
Abstrac:
Territory introduces inequalities. Its physical and especially, human characteristics make impossible a real equality of opportunities. The residence place of each person and the way they live their reality (determined by their environment), contributes, along with other factors, to explain social differences and the divergent trajectories of life for many people, particularly young people.

In this article, we systematize and validate the community dimension of the intervention from territory, analyzing the keys of intervention with teenagers in conflict with law in the municipality of Burjassot (Valencia). This investigation is based in case studies and involves the systematization of a professional practice, using secondary data analysis and focused interviews, in order to achieve methodological complementarity between quantitative and qualitative data.
\end{abstract}

Keywords: territory, social inclusion, community intervention, teenagers in conflict with law.

\section{Resumen:}

El territorio introduce desigualdades. Sus características físicas, y sobre todo humanas, hacen imposible la igualdad de oportunidades real. El lugar de residencia de cada persona y la forma en que experimenta o vive su realidad (determinada por su entorno) contribuye, junto con otros factores, a explicar las diferencias sociales y las divergentes trayectorias de vida de muchas personas, en particular de los jóvenes. 
En el presente artículo, se sistematiza y valida la dimensión comunitaria de la intervención desde el territorio tras analizar las claves seguidas con los adolescentes en conflicto con la ley del municipio de Burjassot (Valencia). Supone la sistematización de una práctica profesional circunscribiéndose la investigación al estudio de casos. Se utiliza el análisis documental y las entrevistas focalizadas, y se concluye en la necesidad de partir de la concepción comunitaria en el proceso de diagnóstico y de intervención.

Palabras clave: territorio, inclusión social, intervención comunitaria, adolescentes en conflicto con la ley.

\section{Article info:}

Received: 15/03/2014 / Received in revised form: 13/06/2014

Accepted: 20/06/2014 / Published online: 20/07/2014

DOI: http://dx.doi.org/10.5944/comunitania.8.2

\section{Introducción}

En la sociedad postmoderna, la vulnerabilidad y el riesgo de exclusión alcanzan a sectores más amplios de la sociedad; los riesgos se han ampliado y diversificado haciéndonos más vulnerables en extensión e intensidad. En este sentido, Castel (1997) señala que la sociedad actual se caracteriza por la consolidación de una extensa zona de vulnerabilidad, antesala de la exclusión. Bourdieu (1999) caracteriza la vulnerabilidad como un estado permanente de precarité, inseguridad de nivel social, incertidumbre del futuro y sentimiento de no controlar el presente que se combina con una incapacidad de construir proyecciones futuras y actuar coherentemente.

El territorio introduce desigualdades. Sus características físicas, y sobre todo humanas, (redes de transporte, equipamientos, usos del suelo, etc.) hacen imposible la igualdad de oportunidades real. El lugar de residencia de cada persona y la forma en que experimenta o vive su realidad (determinada por su entorno) contribuye, junto con otros factores, a explicar las diferencias sociales y las divergentes trayectorias de vida de muchas personas, en particular jóvenes.

Son muchos y diversos los colectivos en situaciones de especial vulnerabilidad, y pocas veces constituyen una prioridad visible de la acción de gobierno. La infancia y adolescencia es uno de los grupos más invisibles y con más dificultades para hacerse oír. En una sociedad caracterizada no sólo por tener grandes grupos excluidos o al margen, sino también por los extensos grupos que viven en la vulnerabilidad y que corren el riesgo de desplomarse en la exclusión, la cuestión a reflexionar es cómo afecta a su infancia y adolescencia, pues la edad se configura como una de las dimensiones de la vulnerabilidad más clara y visible (Pérez-Cosín y Uceda, 2009). 
En este sentido, Zarzuri (2000) revela que los factores de vulnerabilidad en los adolescentes están más relacionados con las contingencias vinculadas a las causas que generan el riesgo (residir en un barrio con elevada tasa de paro y ociosidad), que con el riesgo en sí mismo (el paro/ la ociosidad). Desde esta perspectiva, el tiempo de exposición al riesgo configurará el grado de vulnerabilidad al que se ha sometido un individuo, sobre el que la exclusión diseñará su particular plan de desgaste.

En la actualidad se han generado periferias urbanas que provocan conflictos sociales (con la ley es uno de ellos) de autorrealización personal y de identidad colectiva. La periferia no es sólo un nuevo espacio urbanístico sino también un modo de emocionar y sentir la realidad, y un modo de interrelacionarse e identificarse colectivamente (García Roca, 2004). Coincidiendo con este contexto de intensificación de las desigualdades socio-espaciales, y por tanto de un aumento del número de áreas urbanas desfavorecidas (Atkinson y Kintrea, 2001), el debate sobre los efectos del territorio ha suscitado un interés que va in crecendo.

Los trabajos empíricos de Brooks-Gunn et al. (1993) señalan que vivir en un determinado territorio impacta sobre el comportamiento social, la calidad de vida y las oportunidades de futuro de quienes viven en él, haciendo hincapié en la influencia negativa, especialmente donde existen importantes deficiencias en equipamientos $y$ servicios sociales dirigidos a la ciudadanía (Wilson, 1987; Jencks et al., 1990 y Musterd et al., 2006). Porcel et al. (2011) estudian en qué medida el área residencial es un factor que condiciona la distribución de oportunidades entre la población joven de la Región Metropolitana de Barcelona.

El territorio se configura como un elemento fundamental para explicar la exclusión social. Su análisis es complejo como el propio espacio debido a la multitud de interrelaciones existentes, sinergias y ralentizaciones, por lo que el enfoque interdisciplinar se configura como el más adecuado. Pero si el territorio explica parte de la exclusión social, también es el escenario ideal para la inclusión, fundamentalmente de la población juvenil.

Desde estos postulados, Castells (1995) incide en cómo la globalización del mundo implicaba, de forma paradójica, un fortalecimiento de lo local como única respuesta viable de la ciudadanía ante la pérdida de control de sus propias vidas: lo local frente a lo global. El autor defiende que hay un espacio que se está dando en todas las sociedades en la medida en que éstas se articulan crecientemente en un sistema global.

En el centro de esa transformación se encuentra la aparición de lo que denominó el espacio de los flujos, como forma de articulación espacial del poder y la riqueza en nuestro mundo. Junto o en frente del espacio de los flujos persiste el espacio de los lugares en el que se construye y practica la experiencia, el espacio de la vida cotidiana de la gran mayoría de las personas. Este espacio es cada vez más local, más 
territorial, más apegado a la identidad propia, como vecinos, miembros de una cultura, de una etnia, de una nación.

El espacio local es donde se desarrolla la trayectoria delictiva pero a su vez es el espacio de la intervención social. Es precisamente en él donde se desarrollan las políticas sociales de proximidad que favorecen la convivencia y la integración sobre la base de un territorio. El ámbito local constituye un marco extraordinario para aprovechar las sinergias pues en el territorio confluyen las personas y los grupos, las administraciones públicas con sus diferentes políticas, servicios y programas, las instituciones sociales privadas (sin y con ánimo de lucro), las empresas, los espacios de ocio, etc. En el territorio local despliegan sus políticas de bienestar social los ayuntamientos, es el espacio de referencia de los servicios sociales comunitarios que constituye el único sistema de protección social en España donde la administración local ejerce amplías competencias. (Uceda, 2011).

Sostiene Subirats et al. (2010) que hablar de inclusión social es hablar de ciudadanía. La inclusión social y la ciudadanía operan con lógicas distintas pero estrechamente vinculadas, y una es condición y posibilidad de la otra. En sus cruces, limitaciones y dinámicas se produce la exclusión social y mediante la intervención transformadora puede tejerse la inclusión social. Asimismo, después de analizar diferentes experiencias de intervención social con colectivos, concluye que los tres elementos fundamentales que constituyen la clave de la intervención son: acoger, acompañar y construir autonomía desde el territorio.

En este artículo procedemos a mostrar y analizar los resultados de la investigación desarrollada en el municipio de Burjassot (València) sobre adolescentes en conflicto con la ley ${ }^{1}$ desde el territorio como variable clave para la intervención social, pues es en el mismo donde se puede desarrollar con toda la potencialidad el trabajo social comunitario.

\section{La pertinencia de la intervención desde el territorio (y comunitaria) con los ACL}

Los ACL forman parte de la comunidad. Una manera de contemplar esto consiste en verlos como la causa del delito juvenil en la sociedad, puesto que sin ellos no existiría la delincuencia juvenil.

Algunos expertos dicen que son a su vez el producto de las influencias negativas en la sociedad de la pobreza, las viviendas deficientes, el desempleo, los barrios desfavorecidos, la exclusión social, de ciertos enfoques del ejercicio materno-paternal o de su falta, de una educación demasiado reducida o mal orientada, etc. Otros plan-

\footnotetext{
1 En adelante ACL.
} 
tean que la causa del delito es genética, una manifestación del pecado original o la malévola y egoísta opción del delincuente. Y cada vez son más quienes afirman que las causas del delito radican en una combinación de todos estos factores y las circunstancias sociales presentes en el momento del suceso.

En el plano de la delincuencia y su relación con el territorio, cabe citar las investigaciones deThrasher en 1927 sobre las bandas juveniles y el territorio, la de Shaw y Mckay en 1929 que llevaron al extremo el análisis espacial sobre las áreas delictivas de Chicago, llegando a la conclusión que las características físicas de la zona causan la delincuencia. Es decir, los jóvenes delincuentes no se diferencian sustancialmente de los no delincuentes en sus características de personalidad, inteligencia u otras, sino en los tipos de barrios en los que viven. Determinados barrios ofrecen más oportunidades para la actividad delictiva y en ellos, el comportamiento de algunos jóvenes se aprende y transmite por vía de tradición, consolidándose cuando el individuo se identifica con su mundo delictivo (Picó y Serra, 2010).

Con independencia de cuál sea la causa, la mayoría de la gente da por supuesto que puede hacerse algo, que el delito y la conducta de los jóvenes delincuentes se verán afectados por las respuestas que se les otorguen en los niveles nacional y de la comunidad local. La elección de la causa influirá en las respuestas que se escojan, desde la educación especial, el tratamiento psicológico, la intervención social de distintos tipos, los planes de empleo, etc., combinados con tácticas como el circuito cerrado de televisión y la vigilancia del barrio, hasta los enfoques penales como encerrar a los jóvenes en centros de reeducación (Smale, Tuson y Staham, 2000).

En el trabajo social, la intervención comunitaria es una estrategia basada en el principio de unidad del sujeto en su contexto más cercano, y ello no es nuevo para el trabajo social, pues ya Mary Richmond, en su Social Diagnosis (1917), proponía una concepción de trabajo en la que primaba la consideración de la persona en su ambiente. De Robertis y Pascal (1994:13), inciden que el abordaje colectivo de los fenómenos sociales en trabajo social nos permite designar "las necesidades o los problemas que atañen o que conciernen a más de una persona, y se habla entonces de necesidades colectivas y de problemas colectivos"; es por ello que nuestra investigación ubica al adolescente en conflicto con la ley en su territorio de residencia:

“Toda persona, incluso aislada, forma parte de los grupos que existen en la vida social. Se la tiene, también, que ubicar en su entorno o contexto social particular: todos vivimos en un barrio, en una ciudad, en una región particular. Este entorno tiene una vida cultural, una vida asociativa, deportiva, comercial, educativa, política, económica, etc., en el seno de las cuales el individuo evoluciona, se realiza como persona, se debate y lucha". (De Robertis et al., 1994:15).

El trabajo social ha configurado el espacio de lo comunitario o colectivo como el espacio de lo local (Hamzaoui, 1997). Un espacio privilegiado donde lo global puede 
ser observado y analizado, y desde donde se pueden diseñar estrategias de intervención local. En la configuración de la lógica de lo local se muestra la nueva cuestión social, y es en ella donde el trabajo social ha desarrollado históricamente sus procesos de debate, análisis e intervención:

“El postulado es que lo local y el territorio, como lugares de toma de conciencia de los fenómenos de precarización y de marginalización, son terrenos de acción relativamente controlados, y se puede deducir que es localmente como estos fenómenos pueden ser resueltos". (Hamzaoui, 2005:81).

El abordaje desde la lógica comunitaria o colectiva conlleva el análisis desde y en los escenarios. Los escenarios cotidianos son "el barrio donde residimos, la ciudad en donde estamos empadronados o la comunidad como identidad cultural, lingüística o religiosa". (Pérez Cosín et al., 1999:92). En estos escenarios se produce la infracción, la intervención policial-judicial y social, y por ello son espacios idóneos de análisis puesto que en su funcionamiento y en el desarrollo de su acción pueden ser una nueva fuente de vulnerabilidad y exclusión, o de fortalecimiento del sujeto y sus redes.

Marchioni (1989) considera que la intervención comunitaria es una de las metodologías de intervención social delTrabajo Social que mejor permiten trabajar en la prevención de la exclusión social, así como en inicio de procesos de inclusión social. La intervención en, para y con la comunidad supone partir de cuatro elementos estructurales: el territorio, la población, las demandas y los recursos. La población la forman los ciudadanos, las administraciones públicas y los recursos técnicos (Pelegrí, 1990).

Desde el trabajo social comunitario se contribuye a la integración y el apoyo social (Navarro, 2004) desde la base de las relaciones, que muchos autores identifican como bases fundacionales del propio trabajo social (Barbero, 2002). En este sentido, el trabajo social utiliza el concepto de comunidad para: a) el estudio de inserción social del individuo; b) el estudio del acceso a recursos sociales; y c) el estudio del conflicto y desarrollo comunitarios (Sancho, 2009).

Desde estos postulados se realiza la intervención con los ACL desde los servicios sociales municipales o comunitarios de Burjassot que a continuación se desarrolla.

\section{El diseño de la investigación}

La aproximación al objeto de investigación se realiza desde los parámetros de la intervención comunitaria, muy propia del trabajo social. Se parte del estudio de caso, metodología de gran tradición en la sociología, antropología y trabajo social (Platt, 1988). Como señala Yin (cit. en Castro, 2010:36), los casos son "una investiga- 
ción empírica que estudia un fenómeno contemporáneo dentro de su contexto real, cuando las fronteras entre el fenómeno y el contexto no son evidentes, y en la que se utilizan múltiples fuentes de evidencia".

Se propone un estudio de caso explicativo que pretende revelar la importancia de un marco de intervención en una organización concreta y en un territorio delimitado. Los casos se escogen por su capacidad explicativa y no por su representatividad estadística (Bonache, 1999).

Se realiza el análisis del programa de intervención con ACL en medio abierto que se desarrolla desde el departamento de servicios sociales del ayuntamiento de Burjassot en la Comunitat Valenciana (España). En este sentido, podemos considerar que es una investigación aplicada desarrollada para validar o modificar una forma de intervención. Se analiza el perfil de los adolescentes en conflicto con la ley y la metodología de intervención.

Se ha considerado pertinente la utilización de dos técnicas en el proceso de investigación: el análisis de datos secundarios y la entrevista focalizada. En este sentido, se produce una complementariedad metodológica entre datos cuantitativos y cualitativos que posibilitan la obtención de diferentes perspectivas desde las que enfocar y comprender el fenómeno (Denzin, 1978).

La explotación de datos secundarios es posiblemente una de las técnicas más extendida en cualquier investigación emprendida desde las ciencias sociales. El cúmulo de informaciones que se hallan recogidas por instituciones sin propósitos específicos de investigación social, nos proporciona un abigarrado conjunto de datos desde los que describir e interpretar la acción de las instituciones (Almarcha, 1969).

En este caso, se han utilizado las memorias anuales del programa de medidas judiciales en medio abierto² del Ayuntamiento de Burjassot del periodo 2004 al 2009. Las memorias anuales resultan una fuente de datos secundarios muy útil, pues nos permite realizar una aproximación descriptiva al fenómeno desde los datos recogidos por la institución. En estas memorias hallamos datos que definen la metodología de intervención utilizada en el programa de MM.JJ.MA, el perfil de los ACL del municipio de Burjassot y el estudio sobre el territorio de los ACL.

En el siguiente cuadro observamos los indicadores por dimensión extraídos de las memorias, y analizados.

2 A continuación P.MM.JJ.MA. 


\section{CUADRO 1. Indicadores de análisis de las memorias anuales del P.MM.JJ.MA estudiadas}

\section{DIMENSIÓN}

\begin{tabular}{l|l|}
\hline Ejecución de & $\begin{array}{l}\text { Medidas judiciales derivadas al programa. } \\
\text { medidas }\end{array}$ \\
& $\begin{array}{l}\text { Notodonores con los que se interviene. } \\
\text { intervención). } \\
\text { Recursos propios del programa y externos a él, protocolos de } \\
\text { coordinación y colaboración. } \\
\text { Recursos humanos. }\end{array}$ \\
Perfil de los ACL & $\begin{array}{l}\text { Características socio-familiares de los adolescentes: nivel familiar, } \\
\text { educativo, laboral, grupo de iguales, comunitario. } \\
\text { Características personales de los adolescentes. }\end{array}$ \\
\cline { 2 - 2 }
\end{tabular}

Fuente: elaboración propia a partir de las memorias del P.MM.JJ.MA.

Asimismo, se ha utilizado la entrevista focalizada para recoger las informaciones y percepciones del colectivo de profesionales. Se ha seguido el modelo de Patton (1990), entrevista basada en guión, caracterizada por la preparación previa de los temas a tratar y por tener el entrevistador libertad para obtener y formular las preguntas. De acuerdo con Valles (1999), se han diseñado desde los tres principios muéstrales de heterogeneidad, accesibilidad y representación entrevistando a informantes clave que intervienen o han intervenido con los ACL del municipio de Burjassot, no sólo desde el ámbito de la ejecución de las medidas judiciales, sino desde otros ámbitos: educativo, centros de día, servicios sociales comunitarios, etc., obteniendo así una visión más amplia y global del escenario social de los ACL del municipio y las vías de intervención con ellos.

Se han analizado las entrevistas ${ }^{3}$ de ocho profesionales, para la selección de los cuales se han considerado diversas características que debían poseer: primera, pertenecer al grupo de profesionales que se encargan de la ejecución de las medidas judiciales en medio abierto, impuestas según la LORPM 5/2000, en el municipio de Burjassot. Segunda, si no pertenecen al primer grupo, ser otros expertos que posean una trayectoria y conocimiento específico del tema: trabajadores/as sociales, psicólogos/as, profesores/as, educadores/as de centros de menores, centros de día, servicio de atención a la familia e infancia, etc., y que desarrollan o han desarrollado su intervención con adolescentes del municipio de Burjassot. Y por último, habían de cumplir el criterio de experiencia profesional en su campo de un

\footnotetext{
3 El tratamiento de las entrevistas se ha realizado con el programa informático para datos cualitativos MAXqda 2007.
} 
mínimo de cinco años para disponer de suficiente experiencia y evitar los sesgos de novedad.

La relación de los profesionales entrevistados especificando el ámbito laboral en el que desarrollan su intervención y los años de experiencia en el mismo, se muestra en el cuadro siguiente.

\section{CUADRO 2. Relación de profesionales entrevistados con indicación del ámbito laboral y años de experiencia en la profesión}

\begin{tabular}{l|l|c}
\multicolumn{1}{c}{\begin{tabular}{c}
\multicolumn{1}{c}{ PERFIL } \\
PROFESIONAL
\end{tabular}} & \multicolumn{1}{c}{ UBICACIÓN } & \multicolumn{1}{c}{$\begin{array}{c}\text { AÑOS } \\
\text { EXPERIENCIA }\end{array}$} \\
\hline Trabajadora Social & $\begin{array}{l}\text { Servicios Sociales Generales Barrio 613 } \\
\text { Viviendas } \\
\text { Instituto Educación Secundaria “Federica } \\
\text { Montseny" Barrio 613 Viviendas } \\
\text { Profesora }\end{array}$ & 14 años \\
$\begin{array}{l}\text { Psicólogo Formación } \\
\text { e Inserción Laboral } \\
\text { Trabajadora Social }\end{array}$ & $\begin{array}{l}\text { Centro de Formación Municipal (CEMEF) } \\
\text { Trabajador Social }\end{array}$ & 7 años \\
Trabajador So cial & $\begin{array}{l}\text { P.MM.JJ.MA de los Servicios Sociales } \\
\text { Centro de día "Los Blos Servicios Sociales } \\
\text { Viviendas }\end{array}$ & 12 años \\
\cline { 2 - 3 } & & 8 años \\
\end{tabular}

Fuente: elaboración propia.

\section{Los contextos de la intervención}

El contexto territorial, legal e institucional establecen los parámetros de la intervención. A continuación se explican brevemente.

\subsection{El contexto territorial de la intervención}

El contexto territorial de la intervención y por ende de esta investigación, es el municipio de Burjassot, situado a $4 \mathrm{~km}$. de la ciudad de Valencia, en el extremo sur de la comarca de L'Horta Nord formando parte del área metropolitana de esta ciudad con una población de 38.170 habitantes y una densidad de 11.236,79 (Hab/Km).

A excepción del centro histórico, su desarrollo se produce principalmente en los años 60-70 fruto de las oleadas migratorias procedentes principalmente de Castilla La Mancha y Andalucía. En la década de los años 70-80, se construye el Barrio de las 
"613 Viviendas" ${ }^{4}$ para dar alojamiento a la población de chabolistas y de infravivienda de la comarca; y pese a las inversiones y las actuaciones de la administración, concentra graves problemas de exclusión social, paro, desestructuración familiar, drogas y delincuencia juvenil (Monje y Uceda, 2003).

El barrio se constituye con los años en un ejemplo de exclusión social asociado al territorio, donde se intensifican las desigualdades socio-espaciales tal y como las describen Atkinson y Kintrea (2001). Pronto, vivir en el barrio provoca un fuerte impacto en el comportamiento social, la calidad de vida y las oportunidades de futuro de quienes viven en él (Wilson, 1987). De acuerdo con Herin (2008), vivir en barrios sensibles marca las personalidades de los residentes y les conduce a la autoexclusión, condicionando sus relaciones sociales con el resto de residentes de la ciudad que rehúyen de esos territorios por miedo o temor a sus residentes.

La degradación continua y permanente del barrio afectó de forma muy determinante a la población infanto-juvenil, buena parte de la cual reprodujo las actividades marginales de los adultos (abandono de la escuela, consumo de drogas, empleos irregulares, delincuencia juvenil, etc.). Las nulas expectativas de futuro de las familias se reprodujeron socialmente en la visión de la población infanto-juvenil, lo que configuró un entramado social y de expectativas estructurales y subjetivas de marginación social que condicionaron la socialización (Romero, 2010).

En este sentido, rápidamente participaron de la subcultura (término acuñado por Thrasher, Shaw y Mckay y profundizado por Cohen) de sus barrios, donde se dan sistemas normativos diferentes al resto de la ciudad. Esto supone para ellos el aprendizaje de forma ordinaria de las conductas delictivas, pues son observables en sus barrios, accesibles a su grupo de iguales y no reprobadas por la comunidad (Morente, 2008). Sin duda, se formó el habitus (Bourdieu, 1991) con el que muchos adolescentes y jóvenes se socializaron, ya que determinadas condiciones económicas y sociales determinaron las conductas de las personas.

Dentro del municipio de Burjassot, éste ha sido el barrio (también sus zonas adyacentes) que ha concentrado la residencia habitual de los ACL y fundamentalmente de aquellos que han consolidado sus trayectorias delictivas como se observa en el mapa que se muestra a continuación.

4 A continuación BAP 613. 
Figura 1. Mapa de Burjassot y sus Barrios. Residencia de los ACL en el año 2009

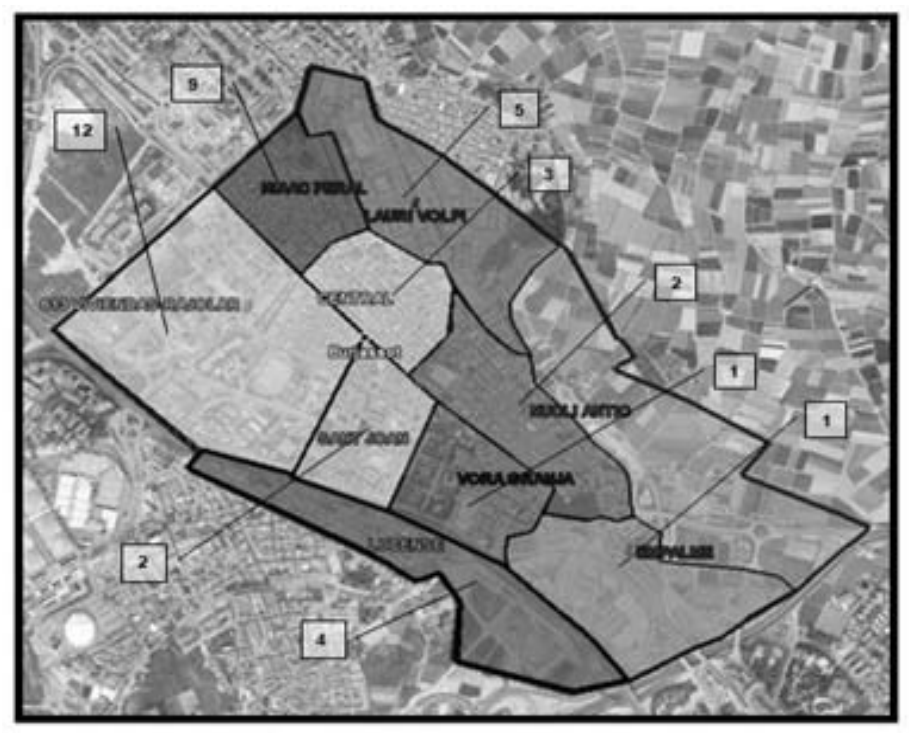

\begin{tabular}{|c|c|c|}
\hline \multicolumn{3}{|c|}{2009} \\
\hline \multirow[t]{2}{*}{ BARFOO } & \multicolumn{2}{|c|}{$\begin{array}{l}\text { N" ME NORES } \\
\text { CONFLICTO LEY } \\
\end{array}$} \\
\hline & CAICOS & CHICAS \\
\hline $\begin{array}{l}\text { 613VIVIENDAS - } \\
\text { RAUOLAR }\end{array}$ & 10 & 2 \\
\hline ISAAC PERAL & $=$ & 1 \\
\hline CENTRALL & 3 & 0 \\
\hline LAURA VOLPI & 4 & 1 \\
\hline NUCLIANTIC & 2 & 0 \\
\hline SANT JOAN & 2 & 0 \\
\hline VORA GRANSA & 1 & 0 \\
\hline LUCENSE & 2 & 2 \\
\hline EMPALME & 0 & 0 \\
\hline BURUASSOT TOTAL. & & \\
\hline
\end{tabular}

Fuente: elaboración propia a partir de las memorias del P.MM.JJ.MA.

\subsection{Contexto legal e institucional de la intervención}

El dispositivo, la orientación y los marcos de la intervención con los ACL de Burjassot, no sólo están marcados por el contexto territorial sino también por el marco jurídico establecido por los convenios internaciones firmados por el Estado Español, la legislación estatal y autonómica aprobada.

Las Naciones Unidas, en las Reglas de Beijing (1985), abogan porque la administración de justicia de menores ha de situarse en el marco general de justicia social, de manera que contribuya a la protección de los jóvenes y al mantenimiento del orden pacífico de la sociedad. Las Reglas de la Habana (1990) inciden en que todo tipo de detención se ha de realizar para fomentar la integración en la sociedad, ya que la privación de libertad de un menor deberá decidirse como último recurso, por el período mínimo necesario y limitarse a casos excepcionales. Y las Reglas de Tokio (1990) señalan la necesidad de promover la participación de la comunidad en la gestión de la justicia penal.

La ley $5 / 2000$, de responsabilidad penal de los menores española, incide que la finalidad de la misma es el interés superior del menor así como la asunción de la responsabilidad de los hechos. Se asume el principio de intervención penal mínima y de oportunidad que permite una verdadera desjudicialización e implanta un modelo flexible que accede a aplicar la medida más adecuada al ACL en función de sus pro- 
pias carencias educativas manifestadas en la comisión de hechos delictivos. Posibilita modificar el tratamiento, reducirlo e incluso dejarlo sin efecto si con ello se contribuye a lograr la reeducación de los menores. Incorpora los principios y medidas del modelo de justicia reparadora, así como un gran elenco de medidas considerando el internamiento como última ratio del sistema. Con ella se abandona definitivamente el modelo tradicional tutelar, que inspiró leyes anteriores, por el denominado modelo de responsabilidad o educativo-responsabilizador.

Esta ley ha sido reformada en numerosas ocasiones (Ley $4 / 2000$, Ley $9 / 2000$, Ley $15 / 2003$ y Ley $8 / 2006$ ) y de acuerdo con numerosos expertos cada una de las reformas ha intensificado su rigor punitivo, perdiendo flexibilidad y primando los elementos retributivos, intimidatorio, etc. (Cano, 2006).

La ley 12/2008, de 3 de julio, de Protección Integral de la Infancia y la Adolescencia de la Comunitat Valenciana crea el marco para el sistema de reeducación valenciano, posibilitando entre otras cuestiones, la ejecución de medidas judiciales desde las instituciones más próximas a los $\mathrm{ACL}$ como son los ayuntamientos, encuadrándose en los departamentos de servicios sociales municipales y siendo la figura de referencia los trabajadores sociales. Su ubicación en los servicios sociales comunitarios permite desarrollar la intervención desde el trabajo social comunitario.

En el ayuntamiento de Burjassot, el P.MM.JJ.MA se enmarca junto con otros recursos (servicio de atención a la familia e infancia, programa municipal de absentismo escolar y centro de día de menores) en el Área del Menor del departamento municipal de servicios sociales y dispone de dos trabajadores sociales para su desarrollo.

La legislación exige a la institución de referencia y a sus profesionales ocuparse de la ejecución de las medidas judiciales, sin establecer más marco de actuación que el seguimiento individual del ACL y la remisión de los oportunos informes de ejecución de medida a la institución autonómica y los juzgados de menores. No se incorpora como marco de intervención social la familia, el grupo y por supuesto la comunidad (legal no puede ser por el principio de responsabilidad).

De acuerdo con Barriga (2000), cabe distinguir entre procedimiento legal y el proceso de intervención del trabajador social. Del procedimiento, el autor plantea que es predecible, con un principio y un final identificables y con paso predefinido (entiéndase en este caso el expediente judicial). Por el contrario, hace referencia al proceso diciendo que carece de toda posibilidad de predicción absoluta y no es lineal dado que los acontecimientos que lo forman pueden darse en espacio y tiempos diferentes. Por tanto, los procesos son incontrolables por uno o varios profesionales, y es esa la complejidad de la intervención, donde lo individual es colectivo y lo colectivo es individual, y donde se diferencia entre la acción sobre el expediente judicial y la intervención con el ACL. 
El procedimiento está diseñado, es decir, cómo y cuándo se deben hacer los informes de seguimiento, cómo y cuándo enviarlos al juzgado pertinente, etc. pero no la intervención que ha de realizarse con los ACL. Ello dependerá de los recursos pero también de la mirada de cada equipo de intervención, de su adscripción territorial, experiencia previa, etc. (Uceda, 2012).

\section{Los resultados: el perfil social de los ACL de Burjassot y el proceso de intervención}

A continuación pasamos a describir el perfil de los ACL de Burjassot y sus problemáticas para así posteriormente explicar las claves de la intervención comunitaria planteada. Desde nuestro planteamiento, el perfil condiciona la intervención, por ello es importante dedicarle unas breves líneas.

Hemos diferenciado entre las siguientes dimensiones: individual, social, familiar, educativa-laboral y de entorno, todas ellas forman parte del mundo de los ACL de Burjassot, en función de cada uno, se mostrarán unas u otras y en intensidad diferentes, pero podemos afirmar que son su complejo ecosistema si habláramos desde la perspectiva ecológico-sistémica de Bronfenbrenner (1987). Desde esta perspectiva, la desprotección infantil, la vulnerabilidad y exclusión de los adolescentes pueden ser comprendidas si se considera como un producto final de una disfunción fundamental en un complejo ecosistema con numerosas variables interactuando. Este modelo considera al individuo en su red de interacción actual (contexto), dependiendo la relación entre sujeto y entorno a una dinámica circular de influencias recíprocas. Los factores ambientales moldean el desarrollo y el comportamiento humano de tal forma que éste tiende a hacerse congruente con las demandas situacionales.

La descripción se ha realizado a partir de un vaciado de las memorias señaladas del programa de medidas judiciales.

\section{a. Dimensión individual, familiar y social}

Los indicadores que aparecen en la figura 2 ubican a los ACL de Burjassot nítidamente en contextos de vulnerabilidad y exclusión social, en función del número de indicadores y de su intensidad se encontrará en una situación u otra (Raya, 2006). De forma habitual, los residentes en el BAP "613 Viviendas" (barrio con la mayor prevalencia ${ }^{5}$ de $A C L$ del municipio) se hallan en situación de exclusión social.

\footnotetext{
5 La prevalencia describe la proporción de la población juvenil delincuente frente a la población juvenil del territorio.
} 


\section{FIGURA 2. Dimensión individual, familiar y social}

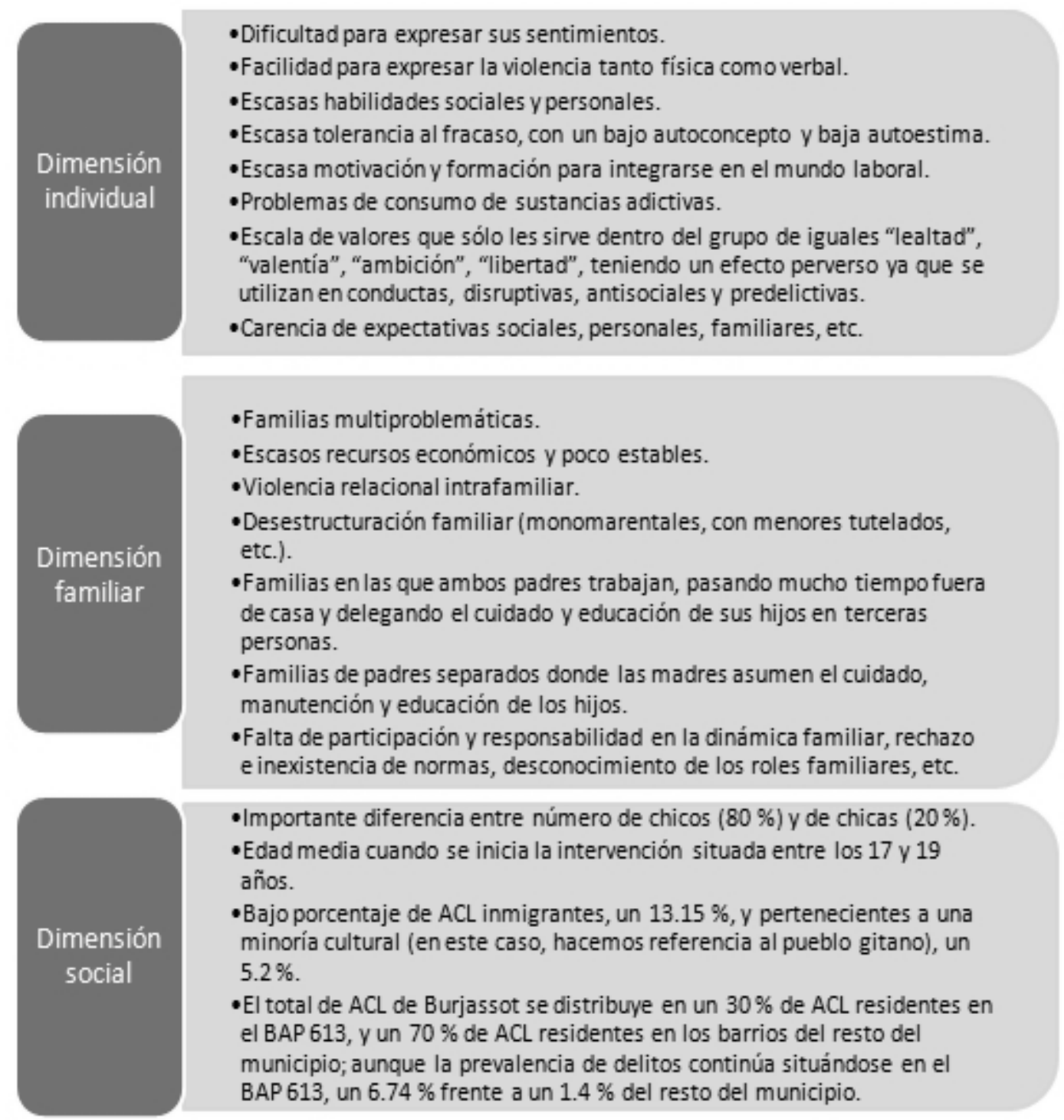

Fuente: elaboración propia a partir de las memorias del P.MM.JJ.MA.

b. Dimensión educativa y laboral

La trayectoria educativa de los ACL es una trayectoria marcada por absentismo escolar, conflictividad, fracaso y abandono escolar; la media de adolescentes escolarizados en los años estudiados es de un $5.36 \%$ y el nivel de instrucción es muy 
bajo. Si observamos la gráfica 1, podemos vislumbrar un descenso del porcentaje de ACL no escolarizados (de un $37.1 \%$ a un $7.8 \%$ ) y un aumento de los que poseen graduado escolar, PCPI o similar (de un $17.10 \%$ a un $44 \%$ ) pero sin alcanzar en ningún momento la mitad de los ACL la formación básica.

\section{GráfICo 1. Nivel de instrucción de los ACL}

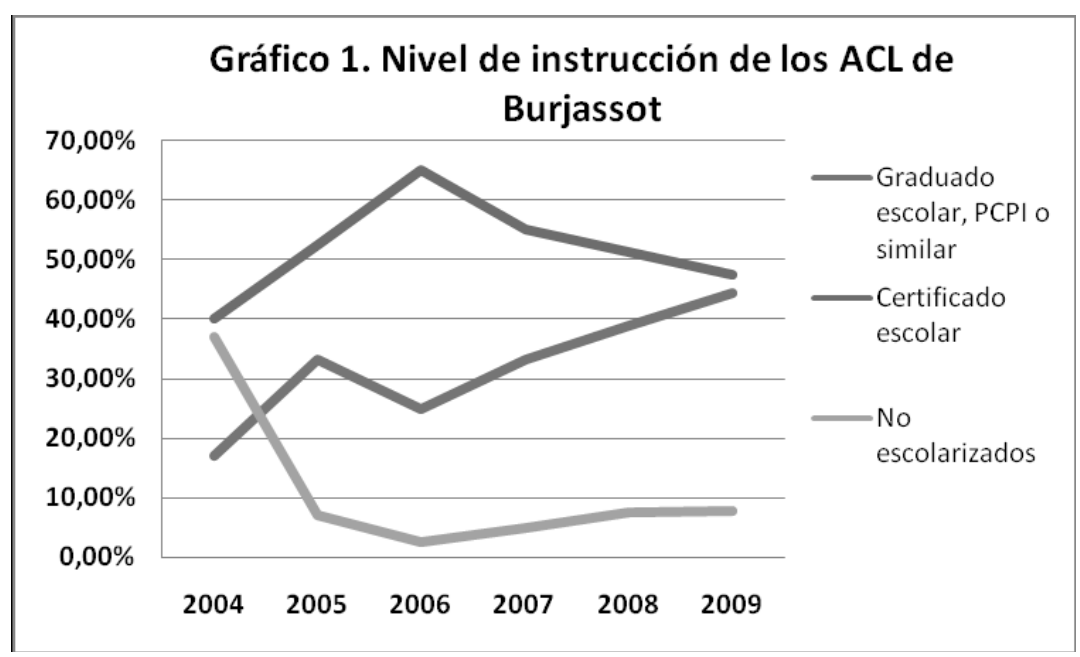

Fuente: elaboración propia a partir de las memorias del P.MM.JJ.MA.

\section{GRÁfICO 2. Situación formativa y laboral.}

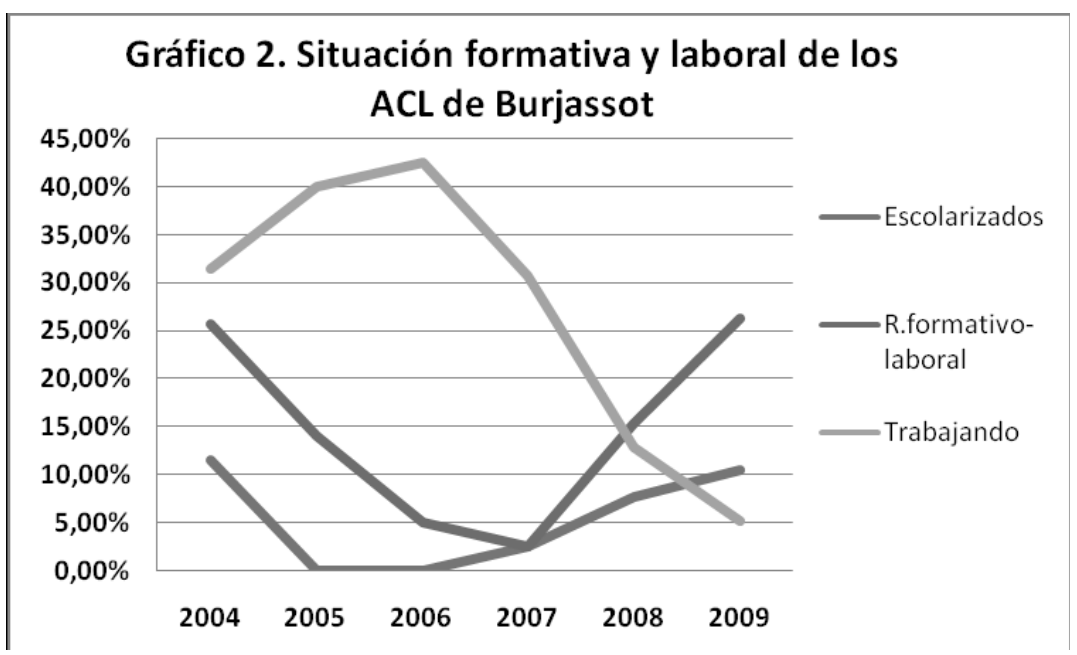

Fuente: elaboración propia a partir de las memorias del P.MM.JJ.MA. 
Todo ello supone un difícil acceso al mundo laboral pues a su escasa formación, carencia de habilidades, y motivación para buscar y mantener un empleo, tal y como podemos ver en la gráfica 2, se une el contexto social de crisis económica. En el año 2009, tan sólo estaban trabajando un $5.2 \%$ de los menores y un $26.3 \%$ estaban en recursos formativos-laborales.

\section{c. Dimensión del entorno}

En la dimensión del entorno, presentan las siguientes problemáticas: falta de alternativas de ocio y tiempo libre saludables, el cual desarrollan íntegramente en la calle, en los parques y sin ningún referente adulto que los guíe y supervise. En el año 2009 , tan sólo un $20.8 \%$ de los menores ocupaban su ocio y tiempo libre con alguna actividad (deportiva, cultural, etc.) relacionada con un ocio saludable. En los años estudiados, el porcentaje de menores con un grupo de iguales conflictivo se sitúa entre un $92 \%$ el año 2004 y un $79 \%$ el año 2009.

\section{GráfICo 3. Grupo de iguales de los ACL de Burjassot}

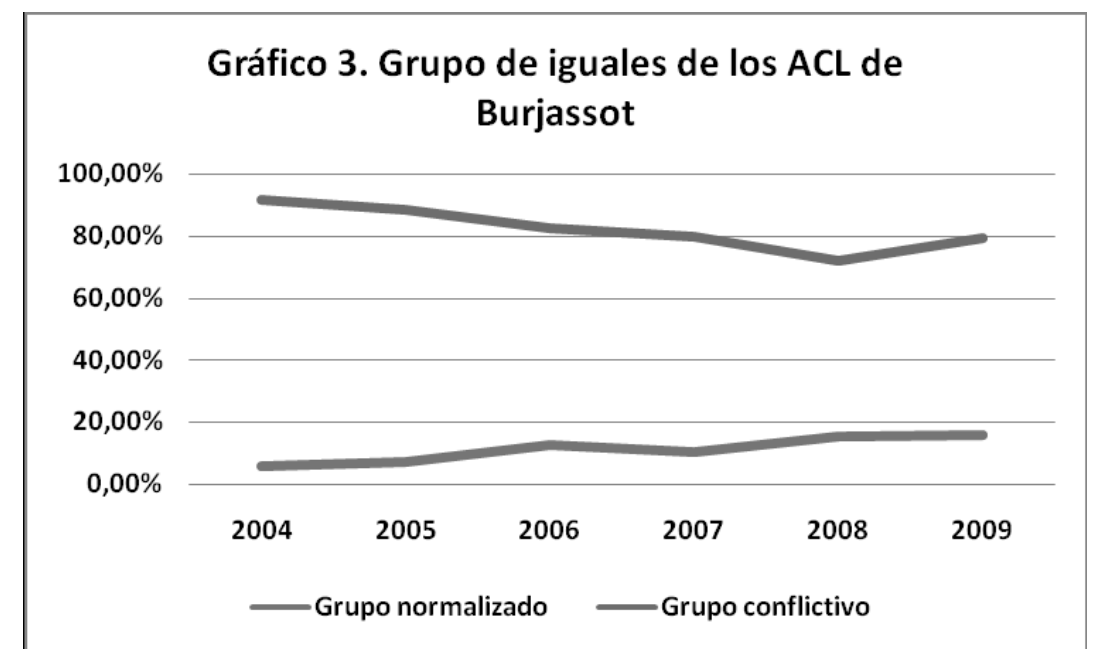

Fuente: elaboración propia a partir de las memorias del P.MM.JJ.MA.

Otra problemática relacionada con la dimensión del entorno es el abuso de sustancias adictivas. En la siguiente tabla podemos ver los porcentajes de los ACL derivados al programa que presentaban un problema de abuso de sustancias adictivas. 
TABLA 1. Porcentaje de ACL con problemas de abuso de sustancias adictivas

\begin{tabular}{cccccc}
$\mathbf{2 0 0 4}$ & $\mathbf{2 0 0 5}$ & $\mathbf{2 0 0 6}$ & $\mathbf{2 0 0 7}$ & $\mathbf{2 0 0 8}$ & $\mathbf{2 0 0 9}$ \\
\hline $74.3 \%$ & $73.8 \%$ & $78.6 \%$ & $87.5 \%$ & $73.9 \%$ & $61.1 \%$ \\
\hline
\end{tabular}

Fuente: elaboración propia a partir de las memorias del P.MM.JJ.MA.

La sustancia más consumida es el cannabis y sus derivados estando vinculado su consumo a otras sustancias como cocaína, heroína y drogas de diseño, etc. existiendo un porcentaje importante de $\mathrm{ACL}$ que presentan un fuerte policonsumo, como se muestra en la siguiente tabla.

TABLA 2. Tipo de consumo de los ACL de Burjassot

\begin{tabular}{l|rrrrrr|} 
& $\mathbf{2 0 0 4}$ & $\mathbf{2 0 0 5}$ & $\mathbf{2 0 0 6}$ & $\mathbf{2 0 0 7}$ & $\mathbf{2 0 0 8}$ & $\mathbf{2 0 0 9}$ \\
\hline Cannabis & $100 \%$ & $80,6 \%$ & $87,9 \%$ & $100 \%$ & $100 \%$ & $100 \%$ \\
Cocaína & $84,6 \%$ & $67,7 \%$ & $69,7 \%$ & $78,6 \%$ & $47,1 \%$ & $81,8 \%$ \\
Heroína & $23,1 \%$ & $16,1 \%$ & $15,2 \%$ & $14,3 \%$ & $17,6 \%$ & $22,7 \%$ \\
Otras (drogas de diseño, etc.) & $65,4 \%$ & $51,6 \%$ & $63,6 \%$ & $35,7 \%$ & $23,5 \%$ & $59,1 \%$ \\
\cline { 2 - 7 } & & & &
\end{tabular}

Fuente: elaboración propia a partir de las memorias del P.MM.JJ.MA.

Tras esta descripción del perfil de los/as ACL de Burjassot, podemos centrarnos en los fundamentos de la intervención que desde el P.MM.JJ.MA se realiza con ellos y que así se describe en las memorias. La intervención se desarrolla desde la metodología del acompañamiento social adoptando el concepto de Pérez-Eransus (2004:102) "...acompañar es avanzar al lado del otro, compartir un proyecto común...", diferenciándolo del seguimiento, pues el primero es un proceso de desarrollo personal rico y complejo y el segundo es la verificación periódica de la situación. Este acompañamiento incluye facilitar el acceso y la incorporación a dispositivos de otros sectores (educativos, de salud, de acceso al empleo), cosa que no debe entenderse como simple orientación y derivación, sino también como mediación social del acceso y la incorporación.

Para ello, es fundamental la generación de la relación de ayuda, entendida en trabajo social como la intervención desarrollada tendente a hacer pasar a una persona de una situación de dependencia a una situación de autonomía, de una situación de incapacidad a una situación de capacidad (De Robertis, 2003). En definitiva, desde esta metodología se pretende ser un punto de referencia de los ACL y sus familias, superando el marco inicial de intervención explicitado en una medida judicial que se circunscribe al seguimiento. 
El proceso de intervención se inicia con el diseño de un diagnóstico social, donde "la relación terapéutica empática es un ingrediente esencial para facilitar un cambio positivo en jóvenes antisociales" (Richardson, 2001:145). Desde la relación empática, la intervención se centra en ofrecer apoyo social transmitiendo capital humano, cultural, social y material (Culen, Wright y Chamlin, 1999), siendo imprescindible la generación de espacios próximos, afectivos y vinculantes para los $A C L$ (Howe, 1997).

El diagnóstico social que se realiza a los ACL incorpora las siguientes características: a) centrado en el adolescente; b) comprensivo de su realidad; c) holístico (personal, familiar, judicial, político, cultural, laboral, educativo, ocio y tiempo libre, etc.). Se parte del análisis de los factores protectores para potenciarlos y de los de riesgo para disminuirlos, siendo el factor clave de inicio la resiliencia.

La resiliencia ${ }^{6}$ es la capacidad o los recursos que tiene el ser humano de hacer frente a las adversidades de la vida, manteniendo un proceso normal de desarrollo y salir de ellas fortalecido o incluso transformado (Rutter, 1985; Grotber 1996 y Barudy 1998). Permite comprender cómo las personas responden positivamente a las situaciones adversas y cómo usan este conocimiento en el futuro: dentro de sus entornos personales, familiares y comunitarios. Se puede adquirir, es decir, aprender como producto de una interacción positiva entre el componente personal y ambiental de un individuo, por ejemplo, uno de los mecanismos fundamentales es la relación con un adulto significativo que reafirme la confianza en sí mismo, lo motive y sobre todo, demuestre su cariño y aceptación incondicional (Sánchez, 2003).

En el diagnóstico participa el conjunto de profesionales que conocen o han intervenido en la situación ya que habitualmente el $A C L$ es conocido por los servicios sociales, centro escolar, centro de día, etc. Y en base a todo ello, se articulan cuatro estrategias de intervención, las cuales, lejos de ser excluyentes se complementan pues se parte desde el parámetro comunitario es decir, ACL en el territorio, en la comunidad de referencia, en los programas y recursos desplegados, etc.

Por ello, el P.MM.JJ.MA dispone de unos protocolos de coordinación con los recursos del municipio para la inserción de los $A C L$ en al ámbito comunitario y para el desarrollo de varias de las medidas judiciales dispuestas en la ley 5/2000: prestación de servicios en beneficio a la comunidad, tareas socio-educativas, tratamiento ambulatorio (asistencia a salud mental o unidad de conductas adictivas), asistencia a centro de día, etc.

6 El vocablo resiliencia tiene su origen en el término latin resilio, que significa volver atrás, volver de un salto, volver al estado inicial, rebotar. Fue originalmente usado para referirse a la cualidad de elasticidad y plasticidad de una sustancia. 
A continuación, mostramos un cuadro donde quedan reflejados los recursos del territorio con los que el P.MM.JJ.MA ha establecido protocolos de coordinación para actuar sinérgicamente.

\section{FiguRA 3. Coordinación con los recursos del territorio}

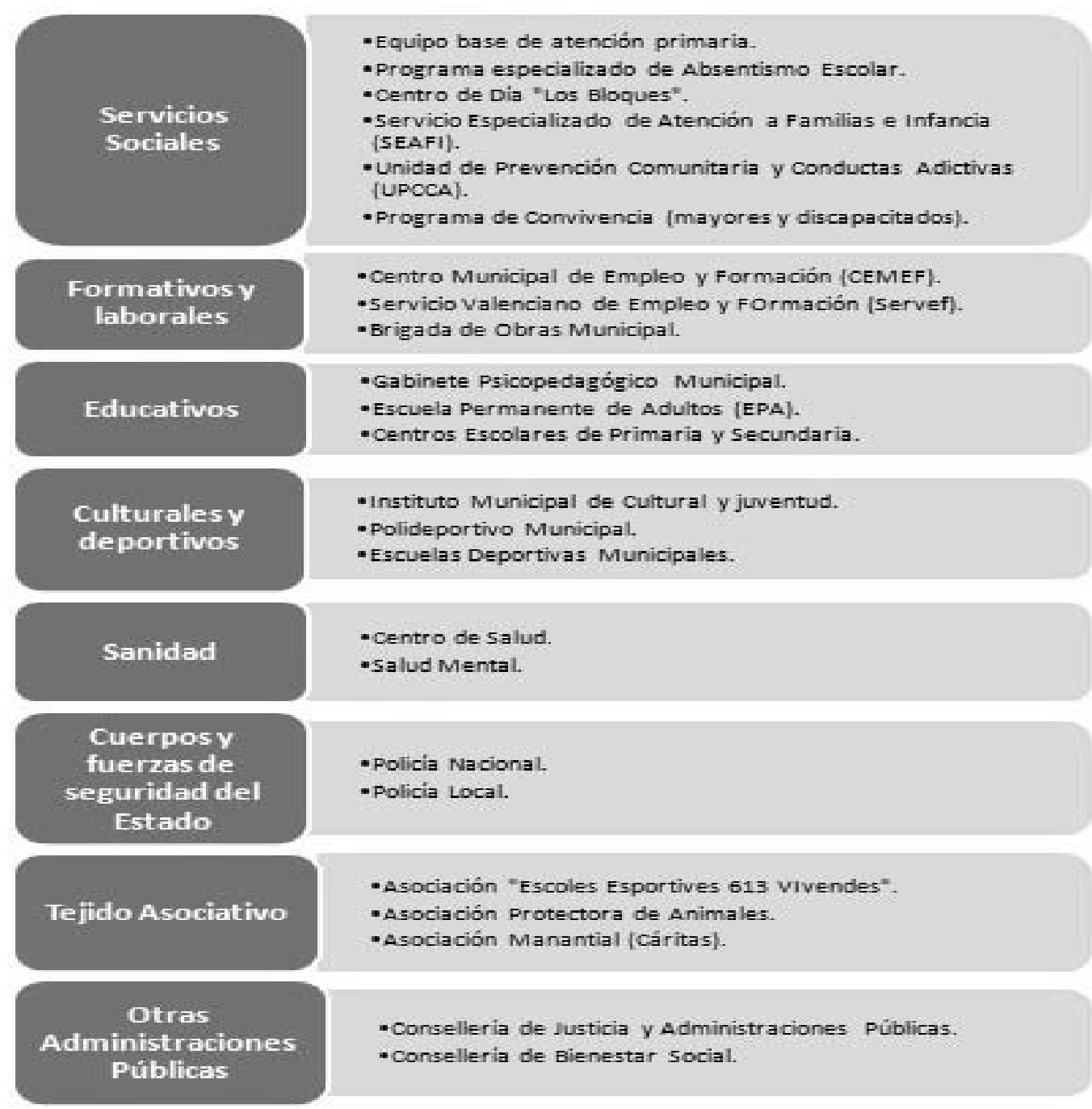

Fuente: elaboración propia a partir de las memorias del P.MM.JJ.MA.

Con el objeto de profundizar en el estudio de caso y validar la intervención que se realiza desde el equipo de Burjassot, analizamos a continuación los datos obtenidos 
de las entrevistas focalizadas realizadas a profesionales del territorio que trabajan habitualmente con los ACL y que pertenecen a los diversos ámbitos que participan en la intervención socio-educativa: formativo-laboral, educativo, centros de día, servicios sociales y medidas judiciales.

En sus discursos, los profesionales mencionan la importancia de descubrir a la persona, conocer sus capacidades y potenciarlas con el fin de que se verifiquen como capaces y valiosas, alejándose así de los modelos asistencialistas. Para ello, es necesaria la existencia de un vínculo que verifique al profesional como un referente para los ACL y las familias con las que intervenir. El factor del vínculo afectivo ${ }^{7}$ es de gran importancia en la relación socio-educativa dado que ésta requiere de un margen donde los adolescentes puedan fiarse y confiarse:

"...Otro tema motivante es el tema afectivo. Un chaval puede ir a un centro sensacional pero la persona que lo atiende, tiene que ser afectiva (...) Estos chavales tienen carencias familiares y buscan aquí esas carencias que tienen. Les falta que les quieran. El profesional que trabaja con jóvenes tiene que trasmitirle interés real por él y sus problemas y saber trasmitirle un "caerle bien". Si en un centro de juventud le entras mal a un chaval, ya todo va mal..." (Trabajadora social Ss.Ss)

“...Es necesario seguir una vinculación afectiva y emotiva con el centro y con las personas, porque yo me he dado cuenta que si el chaval tenia vinculación con el centro, aunque estuviera fracasando en el sentido estricto, él sentía que estaba progresando porque había un espacio para él, una propuesta para él. Desde ese punto de vista se sentía integrado...". (Profesora IES).

Uno de los elementos que los profesionales destacan como fundamental en la intervención con jóvenes es el contemplar la individualidad de cada $A C L$, su personalización, como en el diseño del diagnóstico social del P.MM.JJ.MA, centrado en el ACL. Cada adolescente tiene una situación (personal, familiar, relacional, etc.) específica, unas necesidades y unas demandas propias que no tienen que coincidir necesariamente con las de otros jóvenes por el simple hecho de compartir una cuestión generacional, un barrio o ser ACL:

“...Empiezan a trabajar, no solo pasar lista, sino qué cosas necesita el chaval, que tipo de ayuda le vendría bien, que perfil de tutor... se intenta que en el primer año haya un seguimiento del chaval más personalizado para que el chaval vea que hay alguien que vela por su continuidad..." (Psicólogo recurso formativo-laboral).

“...Deberíamos variar el café para todos, aquí nos juntamos con chavales que son hipertensos y no pueden tomar cafeína, es decir, el café que necesitan es descafeinado...". (Trabajador social MM.JJ).

7 La teoría del vínculo afectivo desarrollada por Bowlby en su trilogía Attachement and loss (1969, 1973, 1983), postula la necesidad humana universal de formar intensos vínculos afectivos con otras personas, desde las familias a los amigos, pasando por el entorno comunitario (vecinos, profesores, etc.). Uceda (2012). 
La intervención con cada adolescente ha de ser personalizada, acorde a sus necesidades y demandas específicas, y adaptarse a la evolución de cada caso partiendo de un diagnóstico como veíamos en las memorias anuales del programa, centrado en ACL y comprensivo de su realidad (su familia, grupo de iguales, contexto, el propio $A C L$, etc.), cosa que exige una estructurada y constante coordinación entre los profesionales que intervienen en el territorio con los $A C L$, de forma que desde el marco de la interdisciplinariedad, se pueda realizar un mejor diagnóstico y planificar una intervención integral sobre el ACL:

“...El trabajador social va a coordinarse con su profesor del instituto o con el psicólogo del colegio, con los centros de menores, también hay una coordinación con la asociación gitana, y con servicios sociales hay una relación de dirección..." (Trabajador social Centro de Día).

“...Entonces yo creo que lo que habría que hacer es tender puentes y hablar, y no ver que somos competencia en eso, sino colaboradores y complementarios..." (Trabajadora social MM.JJ).

Sobre los tipos de intervención, los profesionales también remarcan la existencia de distintas estrategias de intervención desde el territorio complementarias. Entre ellas destacan la intervención familiar, ya que plantean la familia como un elemento decisivo en la situación, trayectoria delictiva y posterior evolución de los ACL:

"...Se pacta de alguna forma con las familias para que colaboren, (...) y se hace un poco de labor de unión familiar (...) y a partir de este año trabajaremos grupos educativos donde la implicación de la familia será absoluta, digamos que será un instrumento educativo más de las familias para educar a los hijos, porque a ellos les faltan habilidades..." (Trabajadora social MM.JJ).

“...El problema de los menores no es más que el problema que tienen las familias que los arrastra a su futura situación..." (Trabajadora social Ss.Ss)

Otro tipo de intervención que resaltan es la grupal, como complemento de la intervención con los ACL sujetos a medidas judiciales utilizando el factor de cohesión y avance que mencionábamos que proporciona el grupo; y como dispositivo de prevención con los adolescentes que sin estar en conflicto con la ley, se encuentra en una situación que los hace susceptibles a ello:

“...Muy importante, la cohesión de grupo no sólo trabajar individualmente, las normas, los pactos a los que llegamos..." (Trabajador social Centro de Día).

“...Es un trabajo individual en un grupo, es como un círculo..." (Psicólogo recurso formativo laboral)

Finalmente, el último tipo de intervención que consideran sustancial es la intervención comunitaria a través de una coordinación con los recursos del territorio. 
Atendiendo a las problemáticas de los ACL descritas anteriormente, una intervención que vaya más allá de una intervención individual, la cual requiere de la existencia de una serie de recursos en el territorio y la articulación de un trabajo en red, que permita una intervención integral y global. Esto se ve favorecido en los contextos territoriales reducidos, dado que el trabajar a nivel de un barrio (BAP 613 Viviendas) o a nivel local (en el caso de Burjassot) permite una mayor coordinación con el ayuntamiento, con las entidades del barrio, con los recursos del municipio:

“... Hay que trabajar en red, es absurdo trabajar sólo desde mi aula y eso en gran parte del profesorado está ausente (...) la perspectiva de trabajo comunitario, de trabajar unos con otros, en red..." (Profesora IES).

“...El modelo bueno es el del contexto comunitario del barrio del chaval..." (Trabajadora social MM.JJ).

Esta intervención comunitaria sobre el territorio se vincula a la intervención con los ACL mediante la figura del trabajador social que combina la coordinación con los distintos recursos y su posicionamiento como referente para ellos a través del vínculo afectivo establecido siendo puente entre los adolescentes y los recursos del territorio que respondan a sus necesidades. De acuerdo con Bergalli y Rivera (2007) esta sociedad se caracteriza por la debilidad de los vínculos sociales y específicamente, de los vínculos entre los adultos y los adolescentes (entre ellos el vínculo afectivo).

Asimismo, el trabajador social se convierte en facilitador de dichos recursos que dependiendo de la necesidad y la demanda del adolescente, buscará, informará, orientará e incluso gestionará la inclusión del adolescente en el recurso más adecuado para él. Además, el reconocimiento que tiene por parte de los adolescentes con los que interviene y la coordinación que establece con los recursos, le permite adoptar el papel de mediador ante cualquier conflicto o problema que pueda surgir, potenciando así el buen funcionamiento y la permanencia de los jóvenes en los recursos:

“...Cuando un chaval da problemas en algún recurso, nos llaman a nosotros...y allá que vamos a mediar para que no los echen, porque nosotros somos el referente tanto para los chavales como para los técnicos del recurso..." (Trabajador social MM.JJ).

“...Les buscamos la EPA, escuelas-taller, TFIL's, lo que pueda ser para que igual con esa pequeña formación puedan entrar en el mundo laboral..." (Trabajadora social Ss.Ss).

De esta forma, se reivindica en este entramado de la intervención comunitaria el trabajo en red, de proximidad en la calle como estrategia clave para intervenir con los ACL, su contexto, familias y grupo de iguales. Un factor importante con estos jóvenes para conocer su realidad e intervenir desde ella es poder desplazarse a los espacios naturales de los ACL y compartirlos con ellos. 
Para los $A C L$, este espacio natural es la calle, los parques, etc., los cuales se encuentran tomados por ellos e incomunicados del mundo adulto. Se rompe con la dinámica del seguimiento clásico, de la intervención restringida al despacho y a entrevistas puntuales y se activa la presencia del trabajador social en el barrio, en la calle que pertenece a los adolescentes, que es donde se adquiere un mayor reconocimiento superando la imagen de referente de la medida judicial, siendo visible y accesible tanto para los adolescentes como para sus familias y grupos de iguales:

"... Creo que en ese sentido hay mucho nominalismo es decir, que hacemos muchas cosas de prevención en la escuela, etc., pero hemos perdido algo, el papel de referencia del trabajo de calle..." (Trabajador social MM.JJ).

Otro de los beneficios que aporta la intervención comunitaria sobre el territorio es la articulación de dispositivos de prevención mediante el trabajo en red. Existe la necesidad de trabajar en prevención en las escuelas, los barrios, los centros juveniles apartándose de la tendencia actual hacia el control, la penalización y la judicialización (De Giorgio, 2005), siendo el escenario idóneo para llevar a cabo dicha prevención, el nivel local:

"...Se ha de trabajar en prevención, institutos, barrios, centros juveniles. No hay que judicializarse, pero aquí, todo es endurecer y prevención cero. Mira, la cosa está así, se endurece la ley, se abandona la prevención, se potencia el medio cerrado y el medio abierto se deja de lado..." (Trabajadora social MM.JJ.MA).

“...Si es que habría que plantearse a dónde se destinan los recursos, es más barata la prevención que los centros, no sé lo que costará ese que han construido al lado de Picassent, sólo les falta construir el puente..." (Trabajador social Centro de Día).

\section{Conclusiones y reflexiones finales}

Los ACL de Burjassot reúnen numerosos indicadores de vulnerabilidad social, y algunos de ellos, específicamente los del BAP "613 Viviendas", de exclusión social. Sin lugar a dudas, la intervención ha de desarrollarse desde la prevención primaria y secundaria en aquellos que se encuentran en situación de vulnerabilidad y en el apoyo a los procesos de inclusión a los que se hallan en exclusión social.

La Ley de Responsabilidad Penal del Menor española exige una responsabilidad individual al $A C L$, poniendo en funcionamiento un procedimiento de intervención individualizante obviando el espacio social donde confluyen individuo y sociedad. Esto plantea una disyuntiva en la intervención con los ACL entre el proceso y el procedimiento, entre lo exigido por expediente y la intervención necesaria para alcanzar el interés supremo del menor, finalidad de la propia Ley 5/2000. 
No podemos obviar que los $A C L$ no se encuentran aislados, pertenecen a una familia, a un barrio, a un municipio, a una ciudad, factores que han condicionado directa e indirectamente su actual situación y con los que se debe contar para modificarla. La relevancia de la intervención comunitaria nos permite articular los recursos del territorio (educativos, culturales, deportivos, tejido asociativo, etc.) y trabajar coordinadamente con ellos para una intervención integral con los adolescentes desde las claves de acoger, acompañar y coadyuvar en sus procesos de autonomía.

La intervención comunitaria desarrollada en un territorio delimitado, en el caso del P.MM.JJ.MA a nivel local, permite a los trabajadores sociales intervenir en los espacios en los que se desenvuelven los $A C L$, utilizando el trabajo en red para movilizar y facilitar los recursos para los jóvenes y ser un mediador entre ellos y los recursos.

La presencia del trabajador social en la calle permite el reconocimiento por parte de la comunidad y de los $\mathrm{ACL}$, así como la generación del vínculo afectivo clave para la intervención social. Sólo desde una concepción comunitaria en el diagnóstico y en la intervención es factible tejer vínculos de inclusión social.

La intervención que se ha desarrollado desde el P.MM.JJ.MA en el municipio de Burjassot ha sido responder al encargo legal, el procedimiento, pero desde el marco del encargo social, el proceso. El adolescente ha de cumplir una medida judicial o varias, y su cumplimiento, desde nuestra óptica, no sólo ha de garantizar lo estrictamente judicial sino que ha de servir para macerar su situación personal, familiar, grupal y de su comunidad. Partimos del desarrollo de la intervención desde el territorio como unidad de análisis, planificación y gestión. El fenómeno social no es producto de determinaciones individuales exclusivamente sino producto de un escenario social pero como sujetos, tanto actores como autores, no se encuentran neutralizados por estas mismas trayectorias "sino que pueden trascender sus circunstancias mediante la creación de nuevos significados y proyectos vitales" (García Roca, 2006:8).

Es fundamental la formación de los trabajadores sociales en la intervención comunitaria, pues es una metodología que nos singulariza como disciplina y profesión que sitúa a la comunidad, a lo local, en el núcleo de la intervención superando el marco de la responsabilidad individual y ubicándose en el de la responsabilidad social. Sólo asumiendo esa mirada, se podrá huir de postulados individualizantes o culpabilizadores limitantes de la acción profesional:

“Porque el trabajo social no empieza y acaba en sí mismo, porque el trabajo social sólo tiene sentido en su función de facilitador y de capacitador de las colectividades para que éstas sean capaces de concienciarse sobre su propia realidad, e implicarse y responsabilizarse activamente en su transformación". (Navarro, 2011:35). 


\section{Bibliografía}

Almarcha, A.; De Miguel, A.; De Miguel, J. y Romero, J. L. 1969. La documentación y organización de datos en la investigación sociológica. Madrid: Fondo para la Investigación Económica y Social de la Confederación Española de Cajas de Ahorro.

Atkinson, R. y Kintrea, A. 2001. "Disentangling Area Effects: Evidence from deprived and non-deprived neighbourhood Effects and Cultural Exclusion". Urban Studies 39: 85-93.

Barbero, J.M. 2002. El trabajo social en España. Zaragoza: Mira editores.

Barriga, L. 2000. "Calidad en los servicios sociales (reflexiones sobre la calidez)." Revista de Servicios Sociales y Política Social 49: 31-62.

Barudy, J. 1998. El dolor invisible de la infancia: una lectura ecosistémica del maltrato infantil. Barcelona: Gedisa.

Bergalli, R. y Rivera, I. (coords) 2007. Jóvenes y adultos: el difícil vínculo social. Barcelona: Universitat de Barcelona.

Bonache, J. 1999. "El estudio de casos como estrategia de construcción teórica: características, críticas y defensas". Cuadernos de economía y dirección de empresas 3:123-140.

Brooks-Gunn, J. Ducan, G.J., Klebanov, P.K. y Sealand, N. 1993. "Do neighbourhoods affect child and adolescent development?". American Journal Sociology, 99: 353-395.

Bourdieu, P. 1991. La distinción. Criterio y bases sociales del gusto. Madrid: Taurus.

Bourdieu, P. 1999. La miseria del mundo. Madrid: Akal.

Bronfenbrenner, U. 1987. La ecología del desarrollo humano. Barcelona: Paidos.

Cano, M. A. 2006. El futuro del Derecho penal juvenil europeo. Un estudio comparado del Derecho penal juvenil en Alemania y España. Barcelona: Atelier.

Castel, R. 1997. La metamorfosis de la cuestión social. Una crónica del asalariado. Barcelona: Paidos.

Castells, M. 1995. La ciudad informacional. Madrid: Alianza.

Castro, E. 2010. "El estudio de casos como metodología de investigación y su importancia en la dirección y administración de empresas". Revista Nacional de Administración, 1 (2): 31-54.

Cullen, F.T.; Wright J.P. y Chamlin, M.B. 1999. "Social support and social reform: A progressive crime control agenda". Crime and Delinquency, 45 (2): 188-297.

Denzin, N. 1978. The research act. A theoretical introduction to sociological methods.New York: Mc Graw Hill.

De Robertis, C. y Pascal, H. 1994. La Intervención colectiva en Trabajo Social. La acción con grupos y comunidades. Buenos Aires: El Ateneo.

García Roca, J. 2004. Políticas y programas de participación social. Madrid: Editorial Sintesis.

García Roca, J. 2006. "Relatos, Metáforas y Dilemas. Para transformar las exclusiones", en $V$ Informe Euhem de políticas sociales. La exclusión social y el estado de bienestar en España, editado por Vidal, F. Barcelona: Icaria.

Grotberg, E.H. 1995. "The international resilience project: Research, application, and policy". Symposium International Stress e Violencia, Lisboa, Portugal.

Hamzaoui, M. (1997):"Trabajo social territorializado. Él: ¿lo social postmoderno?". Revista Servicios Sociales y política social, 40: 43-62. 
Hamzaoui, M. 2005. El trabajo social territorializado. Las transformaciones de la acción pública en la intervención social. Valencia: Servei de publicacions de la Universitat de València y Nau llibres.

Howe, D. 1997. La teoría del vínculo afectivo para la práctica del trabajo social. Barcelona: Paidós.

Hérin, R. 2008. "Violencias en las periferias urbanas francesas. Los disturbios del otoño de 2005". Scripta Nova. Revista Electrónica de Geografía y Ciencias Sociales, 96: 270.

Jenks, C. y Mayer, S.E. 1990. "The social consequences of growing up in a poor neighbourhood"; en Inmer-city poverty in the United States, editado por MC Geary, M. (ed). Washington: Nacional Academy Press.

Marchioni, M. 1989. Planificación social y organización de la comunidad: alternativas avanzadas a la crisis. Madrid: Popular.

Morente, F. (dir); Barroso, I.; Domínguez y Green, G. 2008. El laberinto social de la delincuencia. Jóvenes adolescentes en la encrucijada. Madrid: Dykinson, S.L.

Musterd, S.; Murie, A. y Kesteloot, C. (eds). 2006. Neighbourhoods of poverty: Urban social exclusion and integration in Europe. Londres: Palgrave.

Navarro, S. 2011. Redes sociales y construcción comunitaria. Creando (con) textos para una acción social ecológica. Madrid: Editorial CCS.

Patton, M. Q. 1990. Qualitative Evaluation and Research Methods. London: Sage.

Platt, J. 1988. "What can case studies do?". Studies in Qualitative Mathodology. 1: 1-23.

Pelegrí, X. 1990. "La comunidad, lo comunitario y el trabajo comunitario". Revista de Treball Social. 145: 156-178.

Pérez-Cosín, J. V. (coord.); Gómez, J. y Julve, M. 1999. Trabajo social. Orientaciones y prácticas formativas. València: Gules.

Pérez-Cosín y Uceda, F. X. 2009. "Aproximación teórica a los adolescentes en conflicto con la ley: paradigmas y modelos". Servicios Sociales y Política Social, 87: 71-92.

Pérez Eransus, B. 2004. “El acompañamiento social como herramienta de lucha contra la exclusión social. Documentación social, 135: 89-107.

Picó, J. y Serra, I. 2010. La Escuela de Chicago de Sociología. Madrid. Editorial Siglo XXI.

Porcel, S.; Costa, M.; Fernández, M. y Navarro-Varas, L. 2011. Habitus i Hàbitat: La incidència de la segregació urbana entre la població jove de la Regió Metropolitana de BarceIona. Bellaterra: Institut d'Estudis Regionals i Metropolitans de Barcelona.

Raya, E. 2006. Indicadores de exclusión social. Una aproximación al estudio aplicado dela exclusiónsocial. Bilbao: Universidad del País Vasco.

Richardson, B. 2001. Working with challenging youth. Philadelphia: Brunner-Routledge.

Richmond, M. E. 1995. El caso social individual. Diagnóstico social. Madrid: Talasa.

Romero, C. 2010. "El proyecto de regeneración integral urbana del barrio "613 Viviendas", en Propuestas de intervención socioeducativa con las adolescencias, editado por Pérez Cosin, J.V., Navarro, J.J. y Uceda, F. X. València: Nau Llibres.

Rutter, M. 1985. "Resilience in the face of adversity: Protective factors and resistance to psychiatric disorder." Jounal of child Psychology and Psychiatry, 22: 323-356.

Sánchez, S. 2003. "Resiliencia. Como generar un escudo contra la adversidad". Diario Mercurio, Consultado en www.resiliencia.cl/investig/. 
Sancho, J. 2009. "Por una reconstrucción del concepto de comunidad que sea de utilidad para el trabajo social", en Trabajo social comunitario en la sociedad individualizada, editado por Herández Aristu, J. València: Nau Llibres.

Smale, G.; Tuson, G. y Statham, D. 2003. Problemas sociales y trabajo social. A Coruña: Morata.

Subirats, J.(dir.); Obradors, A.; García, P. Canal, R. 2010. Ciudadanía e Inclusión Social. El tercer sector y las políticas públicas de acción social. Barcelona: Fundació Esplai.

Uceda, F. X. y Monje, M. 2003. "El barrio de Acción Preferente "613 Viviendas" de Burjassot: El proceso de normalización de viviendas en un Barrio Desfavorecido", en Un lugar para vivir. Experiencias de exclusión residencial y de cómo salir de ellas en el Estado Español, editado por Oteiza, V. Pamplona: Universidad Pública de Navarra.

Uceda, F.X. 2011. "Los Servicios Sociales en España: desarrollo y articulación en los nuevos escenarios". Documentación Social, 162, 235-258.

Uceda, F. X. 2012. Adolescentes en conflicto con la ley. Una aproximación comunitaria: Trayectorias, escenarios e itinerarios. Tesis Doctoral. València: Universitat de València.

Vallés, M.S. 1999. Técnicas Cualitativas de Investigación Social. Reflexión Metodológica y Práctica Profesional. Madrid: Síntesis Sociológica.

Wilson, J. 1987. The Truly Disadvantaged. The Inner City, the underclass, and Public Policy. Illinois: University of Chicago Press.

Yin, R. 1981. "The Case Study Crisis: Some Answers". Administrative Science Quarterly, 26: 58-65.

Zarzuri, R. 2000. "Notas para una aproximación teórica a las nuevas culturas juveniles: las tribus urbanas." Revista Última Década, 13:81-96.

\section{Referencias normativas y/o legislativas}

Naciones Unidas. Reglas de Beijing sobre Administración de Justicia de Menores (R. 40/33, de 29 de noviembre de 1985).

Naciones Unidas. Reglas de Riad de prevención de la delincuencia juvenil. (R. 45/112, de 14 de diciembre de 1990).

Naciones Unidad. Reglas de Tokio de Medidas de Régimen Abierto. (R. 45/110, de 14 de diciembre de 1990).

Naciones Unidas. Reglas de La Habana sobre Menores Internados. (R. 45/113, de 14 de diciembre de 1990).

España. 2000. "Ley Orgánica 5/2000, de 12 de enero, Reguladora de la Responsabilidad Penal de los Menores". Boletín Oficial del Estado 11:1422-1441,

España. 2000. "Ley Orgánica 7/2000, de 22 de diciembre, de modificación de Ley Orgánica 10/1995, de 23 de noviembre, del Código Penal, y de la Ley Orgánica 5/2000, de 12 de enero, reguladora de la Responsabilidad Penal de los Menores, en relación con los delitos de terrorismo". Boletín Oficial del Estado 307: 45503-45508.

España. 2000. "Ley Orgánica 9/2000, de 22 de diciembre, que establece que todas las referencias a las Salas de Menores de los Tribunales Superiores de Justicia contenidas en 
la originaria redacción deben entenderse realizadas a las Audiencias provinciales". Boletín Oficial del Estado 307:45522-45526.

España. 2002. "Ley Orgánica 9/2002, de 10 de diciembre, por la que se suspende la aplicación de la Ley Orgánica 5/2000, de 12 de enero, Reguladora de la Responsabilidad Penal de los Menores, en lo referente a los infractores de edades comprendidas entre los 18 y 21 años, hasta el 1 de enero de 2007." Boletín Oficial del Estado 296, 42999-43000.

España 2003. "Ley Orgánica 15/2003, de 25 de noviembre, por la que se modifica la Ley Orgánica 10/1995, de 23 de noviembre, del Código Penal". Boletín Oficial del Estado 283:41842-41875.

España 2006. “Ley Orgánica 8/2006, de 4 de diciembre, la que se modifica la Ley Orgánica $5 / 2000$, de 12 de enero, reguladora de la responsabilidad penal de los menores". Boletín Oficial del Estado 290: 42700-42712.

Comunitat Valenciana. "Ley 12/2008, de 3 de julio de 2008, de la Generalitat, de Protección Integral de la Infancia y la Adolescencia de la Comunitat Valenciana". Diari Oficial de la Comunitat Valenciana 5803:70591-70642. 


\section{ARTICULOS/ARTICLES}

Patient Empowerment and Health online Community: two ways to give the new viability doctor-patient relationship / Cooperación y intercambio de conocimiento en la era de Internet: dos maneras de dar nueva viabilidad a la relación médico-paciente Aurelio Tommasetti, Orlando Troisi y Silvia Cosimato

El territorio y la intervención comunitaria con Adolescentes en Conflicto con la Ley. El Caso del Municipio de Burjassot / The territory and the community intervention with teenagers in conflict with law. The case of Burjassot

Francesc Xavier Uceda i Maza, María García Muñoz y Lucía Martínez Martínez

Págs 25-52

The role of Organised Civil Society in the reduction of social risks: How inequality intervenes in civil society actors' attitudes to co-engagement with migrant citizens in public and community life / El papel de la sociedad civil organizada en la reducción de los riesgos sociales: ¿Cómo la desigualdad interviene en las actitudes de los actores de la sociedad civil hacia el compromiso con los ciudadanos inmigrantes en la vida pública y de la comunidad?

Stella Maris Semino

Meaning as A Core Principle in Social Work Practice / El sentido como principio básico en la práctica del Trabajo Social

Rich Furman, Michelle D. Enterline, Greg Lamphear y Allison E. Shukraft

Trabajo Social Comunitario y Formación en Centros de Trabajo: una propuesta para la inserción de adolescentes problematizados desde la Educación Formal / Social Work Community and Work Training Centers: a proposal for insert troubled adolescents from the Formal Education José Javier Navarro Pérez y Eliseu V. Martínez Muñoz

La construcción de los roles de género y su relación con el estrés crónico y la depresión en las mujeres / The construction of gender roles and their relation to chronic stress and depression in women

Pilar Montesó-Curto

\section{RESEIIAS/REVIEWS}

Almudena Moreno Mínguez (editor). Family Well-Being. European Perspectives / Bienestar Familiar. Perspectivas Europeas, 2013. New York: Springer

(por Emilio Díaz de Mera)

M. Castro Guzmán, J. C. Chávez Carapia y Silvia Vázquez González. Epistemología y Trabajo Social, Tomo I / Epistemology and Social Work, Vol. 1, 2013. Méjico: Conacyt y Acanits (por Paloma Serrano Postigo)

Leticia Cano (coord.). Pobreza y Desigualdad Social. Retos para la reconfiguración de la política social / Poverty and Social Inequality. Challenges for the reconfiguration of social policy, 2013. México DF: Díaz de Santos, Ediciones y UNAM 